\title{
An approach to the study of obesity and depression in a sample of Mexican adolescents in northern Mexico
}

Meza Peña, Cecilia; Pompa Guajardo, Edith Gerardina

An approach to the study of obesity and depression in a sample of Mexican adolescents in northern Mexico

CIENCIA ergo-sum, vol. 25, núm. 3, noviembre 2018-febrero 2019 | e26

Universidad Autónoma del Estado de México, México

Esta obra está bajo una Licencia Creative Commons Atribución-NoComercial-SinDerivar 4.0 Internacional.

Meza Peña, C. y Pompa Guajardo, E. G. (2018). An approach to the study of obesity and depression in a sample of Mexican adolescents in northern Mexico. CIENCIA ergo-sum, 25(3). https://doi.org/10.30878/ces.v25n3a4 


\title{
An approach to the study of obesity and depression in a sample of Mexican adolescents in northern Mexico
}

Una aproximación al estudio de la obesidad y la depresión en una muestra de adolescentes mexicanos del norte de México

Cecilia Meza Peña

Universidad Autónoma de Nuevo León, México

cecilia.mezapn@uanl.edu.mx

Recibido: 23 de marzo de 2017

Edith Gerardina Pompa Guajardo

Universidad Autónoma de Nuevo León, México

edith.pompagj@uanl.edu.mx

\begin{abstract}
:
The study investigates the prevalence of obesity and depression, and the strength of association between variables in a sample of adolescents in the North of Mexico. A sample of 849 adolescents was evaluated with the Depression Scale for Children. The results showed a high prevalence of depressive symptoms in adolescents who are overweight and obese (57.9\%). The Obesity is not related statistically with the Depression rate and no association between variables was found when calculated by gender. The study could not confirm a relationship between obesity and depression, but the high prevalence of depressive symptoms in the studied population is of special interest, no matter the weight group they belong.
\end{abstract}

KEYWORDS: obesity, depression, adolescents, prevalence.

\section{Resumen:}

Se investiga la prevalencia de obesidad y depresión y la fuerza de asociación entre variables en una muestra de adolescentes del norte de México. Se evaluó una muestra de 849 adolescentes con la escala de depresión para niños. Los resultados mostraron una alta prevalencia de síntomas depresivos en adolescentes con sobrepeso y obesidad (57.9\%). La obesidad no se relaciona de manera estadística con la tasa de depresión y no se encontró asociación entre las variables cuando se calculó por género. El estudio no pudo confirmar una relación entre la obesidad y la depresión, pero la alta prevalencia de síntomas depresivos en la población estudiada es de especial interés independientemente del grupo de peso al que pertenezcan.

Palabras ClaVe: obesidad, depresión, adolescentes, prevalencia.

\section{INTRODUCTION}

Depression is one of the leading causes of disability worldwide, and, it could be the second cause of disability by the year 2020, being the first the cardiovascular diseases (De Wit et al., 2010; Murray, \& Lopez, 1996). The manifestation of depression during adolescence has a great impact on the development and welfare of the young, and it tends to persist into adulthood (Rafful et al., 2012). Teens that have experienced an episode of major depression in the past year have an increased risk of suicide (Berenzon et al., 2013; Shaffer et al., 1996). It affects the family and equal relationships, academic performance, and can also exacerbate other health conditions such as asthma and obesity (Goodman, \& Whitaker, 2002; Van Lieshout, \& MacQueen, 2008). Some authors estimated that depression increases three times the risk of obesity (Medina-Mora et al., 2008).

In Mexico, depression occurs more frequently in girls (10.4\%) than boys (5.4\%) (Kessler et al., 2005). The situation is very similar in countries like Colombia and Chile (Posada-Villa et al., 2009; Vicente et al., 2009). In adolescent population (aged 12 to 17 years old), a 7.2\% reported to have experienced a depressive episode in the last year, and half of the cases have been classified as serious (Benjet et al., 2009).

Longitudinal studies show that obesity predicts the onset of depression (Roberts et al., 2003). Both, children and adolescents living with obesity are exposed to the social rejection; discrimination, negative 
stereotyping, and these experiences are related to lower self-esteem, problems with body image among other symptoms of psychological distress (Wardle, \& Cooke, 2005).

Although several studies have highlighted the increased prevalence of depression and other psychological ailments in obese people, the relationship between these variables remains unclear (Carpenter et al., 2000). For example, studies in Iranian population have showed no evidence of relationship between obesity and depression (Askari et al., 2013).

This study analyzes the relationship and the strength of the relationship between obesity and depression in a sample of adolescents in northern Mexico, in order to better understand the population of Mexican adolescents and thereby contribute to the development of intervention programs to help combating the obesity problem in a more comprehensive way.

\section{Method}

\section{1. Study design and participants}

This study uses a descriptive cross-sectional design in a sample of 849 adolescents aged 11 to 16 years, with a mean of 13.17 years $(S D=0.91), 53.5 \%$ girls and $46.5 \%$ boys. All participants attend a school of middle e ducation in a medium socio-economic area of northern Mexico; 33.8\% were at first grade, 33.7\% were at second grade and $32.5 \%$ at third grade.

\subsection{Instruments}

Children's Depression Scale-CDS (Lang, \& Tisher, 1983). This Scale allows a global and specific assessment of depression in children aged 8-16 years. It consists of 66 items, 48 depressive and 18 positive. The two sets of items are retained as independent scales and scored separately, yielding a depressive score $(D S)$ and a positive score $(P S)$. The reversal of the positive items allows for a total score of depression (TSD). The depressive dimension $(D S)$ consists of the following factors: AR-affective response, indicating the mood of the feelings of the subject; SP-Social problems, indicating difficulties in social interaction, isolation and loneliness of the child; SE-Self-esteem, is related to feelings, concepts and attitudes of children in relation to their self-esteem and value; SD-Preoccupation with own sickness and death, refers to dreams and fantasies regarding to illness and death; G-Guilt, refers to self-punishment of the child; and MD-Miscellaneous Depressive items, including depressive issues that could not be pooled to form an entity. Positive dimension $(P S)$ is composed of two subscales: P-Pleasure, which refers to joy, fun and happiness in the life of the child or his inability to experience them; MP-Miscellaneous Positives items, including those positive issues that could not be pooled to form an entity.

Each item is scored on a scale of 1 to 5 points in the direction of depression (from strongly disagree to strongly agree depressive elements, and from strongly agree to strongly disagree on the positive type). The values of internal consistency for both subscales $D S$ and $P S$ were calculated with Kuder-Richardson coefficient $(K-R 20)$, finding values of 0.91 and 0.69 respectively. The analysis of internal consistency in the present study showed an excellent level of internal consistency for the total scale of depression $(\alpha=0.95)$, as well as for the depression subscale $(\alpha=0.95)$ and an acceptable level of internal consistency was obtained in the positive subscale $(\alpha=0.78)$.

Precision scale (Tanita BC Innerscan 418). To record weight a digital scale was used, weighting up to $200 \mathrm{~kg}$ with intervals of 100 grams. It has a system of weighing load cells and an impedance measurement through Bioelectric-500 Ohms. 
Stadiometer (SECA). To record height a wall stadiometer was used with a measuring range of 200 centimeters.

\subsection{Procedure}

The study was carried out at a school of middle education in northern Mexico, with a total population of 1200 students. In this school, at the request of the authorities, we participated in a prevention program about sexual health in 21 classrooms, after finishing this participation we invited the institution to participate in the study.

The study was conducted with ethical approval from the School of Psychology of the Universidad Autonoma de Nuevo Leon, and according to recommendations on ethics in research with human beings made by the American Psychological Association (2002), the present study was carried out relying on the prior informed consent of the adolescents' parents, and the consent of adolescents for voluntary participation.

Once the informed consent was obtained from parents and adolescents, the $C D S$ was used in self-report format and applications were made in the presence of evaluators. When participants finished filling out the questionnaire, they were asked to attend to the measurements registration (height and weight). The measures were taken by a young trainee of the last semester of the Public Health and Nutrition College, using a Tanita scale and a stadiometer. Participants were led to a designated space for this purpose, with adequate control of the environment, and controlling the entry and exit of participants and recording measurements to every person. All students were weighed shoeless and wearing their school uniform, which is lightweight.

As appropriate Body Mass Index (BMI) for each age varies in childhood and adolescence through normal development process, the weight range of the participating adolescents was categorized based on the standards of the World Health Organization (Onis et al., 2007), which establishes that a BMI lower than the 5th percentile (based on the tables given for age and gender) indicates underweight, a BMI between the 5th and 85th percentiles indicates normal weight, between 85 and 95 percentiles the subject is overweight, and BMI values above the 95 th percentile indicates obesity.

Participants who responded incorrectly to more than one random response pattern detection item, data were excluded from analyses. Data were also excluded from individuals following a review of outliers due to the likelihood of an invalid response pattern. From 1,200 students who completed the forms, we finally analyzed data of 849 .

\section{Data analysis}

We calculated descriptive statistics for each demographic variable (age, gender, BMI) and for the subscales in all the different dimensions. Adolescent gender and weight group were our two independent variables of interest. The weight status (healthy weight vs. overweight/obese) and prevalence of depression (yes, no) is examined, and we used the unstandardized logistic regression coefficient odds ratios as a measure of the effect size. We also examine the strength of association between weight and depression separately for boys and girls, given that some studies have reported that gender modifies this association (Blaine, 2008; Merikangas et al., 2012). Healthy weight group (BMI < 85th percentile) is the referent. Statistical significance was set at p-values less than 0.05 (Keppel, \& Wickens, 2004). All analyses were performed using SPSS 21. 


\section{Results}

The population mean BMI was $22.46(S D=4.67)$. The distributions of participants by weight can be seen on Table 1 . Together the groups of overweight and obesity corresponds to $58.3 \%$ of the studied population (495 participants).

TABLE 1

Frequencies and percentages of participants by weight groups

\begin{tabular}{|lcccccc}
\hline & \multicolumn{2}{c}{ Total of participants } & \multicolumn{2}{c}{ Boys } & \multicolumn{2}{c}{ Girls } \\
& \multicolumn{2}{c}{} & \multicolumn{2}{c}{$N=393$} & \multicolumn{2}{c}{$N=456$} \\
\cline { 2 - 7 } & $f$ & $\%$ & $f$ & $\%$ & $f$ & $\%$ \\
\hline Normal weight & 354 & 41.7 & 160 & 45.2 & 194 & 54.8 \\
Overweight & 252 & 29.7 & 117 & 46.4 & 135 & 53.6 \\
Obese & 243 & 28.6 & 116 & 47.7 & 127 & 52.3 \\
\hline
\end{tabular}

Source: Own calculations.

The total score of depression mean in participants was $149.07(S D=35.29)$. The distribution is symmetrical $(S k=0.570, S E=0.084)$, and leptokurtic $(K=0.335, S E=0.168)$. After evaluating the normality of distribution for the depression variable, a value of $Z K S=1.38(p=0.04)$ was obtained (Table 2).

TABLE 2

Total scores of subscales and the total depression scale

\begin{tabular}{|c|c|c|c|c|c|c|}
\hline \multirow{2}{*}{ Depression Subscales } & \multicolumn{2}{|c|}{ Full sample } & \multicolumn{2}{|c|}{ Boys } & \multicolumn{2}{|c|}{ Girls } \\
\hline & $M$ & $S D$ & $M$ & $S D$ & $M$ & $S D$ \\
\hline Total Score of Depression (TSD) & 149.07 & 35.95 & 147.19 & 34.36 & 150.68 & 37.22 \\
\hline Positive Score $(P S)$ & 66.97 & 8.77 & 66.73 & 9.20 & 67.17 & 8.38 \\
\hline Depressive Score $(D S)$ & 108.03 & 31.79 & 105.92 & 29.77 & 109.86 & 33.36 \\
\hline Affective response $(A R)$ & 17.69 & 5.71 & 16.84 & 5.26 & 18.44 & 5.99 \\
\hline Social Problems $(S P)$ & 16.54 & 6.39 & 16.19 & 6.05 & 16.85 & 6.66 \\
\hline Self-Esteem $(S E)$ & 16.28 & 6.27 & 16.11 & 6.15 & 16.42 & 6.38 \\
\hline Preoccupation Own Sickness Death $(S D)$ & 15.69 & 5.15 & 15.95 & 5.10 & 15.47 & 5.19 \\
\hline Guilt $(G)$ & 18.08 & 6.17 & 18.06 & 5.76 & 18.11 & 6.51 \\
\hline Miscellaneous D items $(M D)$ & 23.74 & 6.37 & 22.78 & 5.89 & 24.58 & 6.65 \\
\hline Pleasure $(P)$ & 31.51 & 4.60 & 31.24 & 5.04 & 31.74 & 4.17 \\
\hline Miscellaneous $\mathrm{P}$ items $(M P)$ & 35.46 & 5.19 & 35.49 & 5.21 & 35.43 & 5.18 \\
\hline
\end{tabular}

Source: Own calculations.

Note: $M=$ Mean, $S D=$ Standard Deviation.

In estimating the mean and standard deviations for weight groups, higher means are observed in the overweight and obese group except for the positive score and in its two dimensions. Normal weight girls obtained higher means than boys in the total depressive score and depression subscale, while boys in this weight group had a higher mean in the positive subscale. Overweight and obese girls have higher means than boys in almost all variables, with the exception of one dimension of the depressive subscale, in which boys get higher (Table 3). 
TABLE 3

Means and standard deviations of the depression subscales by weight groups and gender

\begin{tabular}{|lrrrrrrrr}
\hline & \multicolumn{3}{c}{ Normal weight } & \multicolumn{4}{c}{ Overweight / Obesity } \\
\cline { 2 - 10 } Depression Subscales & \multicolumn{3}{c}{ Girls } & \multicolumn{3}{c}{ Boys } & \multicolumn{3}{c}{ Girls } & \multicolumn{3}{c}{ Boys } \\
& \multicolumn{2}{c}{$N=194$} & \multicolumn{1}{c}{$N=160$} & & \multicolumn{1}{c}{$N=262$} & & $N=233$ \\
\cline { 2 - 10 } & \multicolumn{1}{c}{$M$} & \multicolumn{1}{c}{$S D$} & \multicolumn{1}{c}{$S D$} & \multicolumn{1}{c}{$M$} & $S D$ & \multicolumn{1}{c}{$M$} & $S D$ \\
\hline$T S D$ & 146.65 & 34.98 & 145.56 & 34.85 & 153.67 & 38.59 & 148.31 & 34.05 \\
$P S$ & 67.38 & 7.75 & 67.59 & 9.19 & 67.03 & 8.83 & 66.14 & 9.17 \\
$D S$ & 106.03 & 31.45 & 105.14 & 30.26 & 112.69 & 34.49 & 106.45 & 29.48 \\
$A R$ & 17.68 & 5.85 & 16.66 & 5.40 & 18.99 & 6.04 & 16.96 & 5.17 \\
$S P$ & 16.43 & 6.52 & 15.96 & 6.32 & 17.15 & 6.77 & 16.35 & 5.87 \\
$S E$ & 15.53 & 5.99 & 15.84 & 6.312 & 17.08 & 6.59 & 16.29 & 6.04 \\
$S D$ & 15.02 & 4.95 & 15.76 & 5.14 & 15.79 & 5.35 & 16.08 & 5.08 \\
$G$ & 17.58 & 6.03 & 18.07 & 5.68 & 18.50 & 6.82 & 18.04 & 5.82 \\
$M D$ & 23.78 & 6.18 & 22.84 & 5.81 & 25.16 & 6.94 & 22.73 & 5.95 \\
$P$ & 32.03 & 4.02 & 31.60 & 4.88 & 31.53 & 4.27 & 30.99 & 5.15 \\
$M P$ & 35.34 & 4.77 & 35.99 & 5.139 & 35.50 & 5.47 & 35.15 & 5.24 \\
\hline
\end{tabular}

Source: Own calculations.

Note: $T S D=$ Total Score of Depression, $P S=$ Positive $S c o r e, D S=$ Depressive Score, $A R=$ Affective Response, $S P=$ Social Problems, $S E=$ Self-Esteem, $S D=$ Preoccupation with Own Sickness and Death, $G=$ Guilt,$M D=$ Miscellaneous $\mathrm{D}$ items, $P=$ Pleasure, and $M P=$ Miscellaneous P items.

The relationship between body mass index and the different dimensions of the depression scale is estimated, finding that BMI is related to the total depressive score, as well as its two subscales. When analyzing relations by gender groups, the results show that there is a relationship between the BMI in girls and the total depressive score, and the depressive subscale, affective response, social problems, self-esteem, miscellaneous depressive items and pleasure. Relations between BMI and positive score, self-esteem, pleasure and miscellaneous positive items are observed in boys (Table 4).

TABLE 4

Correlations between the depression scale with BMI by gender and the total of participants

\begin{tabular}{|lrrrrrr}
\hline \multirow{2}{*}{ Depression Subscales } & \multicolumn{2}{c}{ Total } & \multicolumn{2}{c}{ Girls } & \multicolumn{2}{c}{ Boys } \\
\cline { 2 - 7 } & \multicolumn{2}{c}{$n=849$} & \multicolumn{2}{c}{$n=456$} & \multicolumn{2}{c}{$n=393$} \\
\cline { 2 - 7 } & \multicolumn{1}{c}{$r$} & $p$ & \multicolumn{1}{c}{$r$} & \multicolumn{1}{c}{$p$} & \multicolumn{1}{c}{$r$} & \multicolumn{1}{c}{$p$} \\
\hline TSD & 0.084 & 0.01 & 0.100 & 0.02 & 0.074 & 0.07 \\
$D S$ & 0.076 & 0.03 & 0.100 & 0.02 & 0.045 & 0.19 \\
$P S$ & -0.071 & 0.04 & -0.036 & 0.22 & -0.118 & 0.01 \\
$A R$ & 0.082 & 0.02 & 0.101 & 0.01 & 0.069 & 0.09 \\
$S P$ & 0.063 & 0.06 & 0.077 & 0.05 & 0.069 & 0.09 \\
$S E$ & 0.108 & 0.00 & 0.146 & 0.00 & 0.096 & 0.03 \\
$S D$ & 0.034 & 0.32 & 0.068 & 0.07 & 0.009 & 0.43 \\
$G$ & 0.040 & 0.24 & 0.064 & 0.09 & 0.003 & 0.48 \\
$M D$ & 0.067 & 0.05 & 0.089 & 0.03 & 0.020 & 0.34 \\
$P$ & -0.086 & 0.01 & -0.082 & 0.04 & -0.081 & 0.05 \\
$M P$ & -0.044 & 0.20 & 0.021 & 0.33 & -0.128 & 0.01 \\
\hline
\end{tabular}

Source: Own calculations.

Note: $r=$ Correlation index, $p=$ significance value, $T S D=$ Total Score of Depression, $P S=$ Positive Score, $D S=$ Depressive Score, $A R=$ Affective Response, $S P=$ Social Problems, $S E=$ Self-Esteem, $S D=$ Preoccupation with Own Sickness and Death, $G=$ Guilt, $M D=$ Miscellaneous Depressive items, $P=$ Pleasure, and $M P=$ Miscellaneous Positive items. 
The strength of association between gender, obesity and the presence of depressive symptoms was analyzed, considering cases of depression those with scores outside the range of the statistically normality in the population (percentile $<19$ and $>85$ ). A $50 \%$ of the adolescents suffer from depressive symptoms, present in $45.5 \%$ of boys and $54.5 \%$ of girls surveyed. However, the estimated risk was not significantly associated with gender $(O R=1.053,95 \% C I=0.793-1.398, p>0.005)$.

The prevalence of depression in adolescents who are overweight and obese was $57.9 \%$, while in the normal weight group was of $42.1 \%$, showing no statistically significant association between variables $(O R=$ $0.976,95 \% C I=0.733-1.298, p>0.005)$.

\section{Discussion}

Many studies show the relationship between depression and obesity, but first we wanted to show the prevalence of these variables in adolescents of northern Mexico. The results show that female adolescents and those who are overweight or obese have higher depressive symptoms than boys and those with normal weight; however the strength of association between variables does not allow considering a greater vulnerability to depression by the condition of obesity or gender. The study coincides with another in which the authors report having found no significant difference in the levels of depression in people with normal weight and obese (Askari et al., 2013).

We must emphasize that the studied population was not seeking treatment for their obesity, and perhaps this factor affects the results reported, since when approached to clinical population seeking help for their problem of obesity, they may have greater emotional distress because of their obesity and therefore these differences are appreciated in correspondence if they're seeking or not for a treatment to their weight problem (Fitzgibbon et al., 1993). However, it is interesting to note that in this population of adolescents, there is a high percentage of them with depression levels outside of the normal curve. Although there are proposals that address the difficulty in properly diagnosing depression in boys' population, it is interesting to note in the present study the high number of cases of boys with depressive symptoms.

Some authors report that few overweight and obese children and adolescents are significantly depressed or have low self-esteem (Wardle, \& Cooke, 2005), however, the present study found a 50\% of the adolescent population with levels of depressive symptoms outside the normal curve, and this is not a low or negligible value, independently of the relationship with weight. A study in children and adolescents living with obesity observed that they are aware of their physical appearance (Smith, \& Perkins, 2008), this awareness could be explained by the mockery and rejection they receive from their peers and it should be taken as a warning sign because these aspects leave them in a condition of greater emotional fragility.

The relationship between depression and obesity is not simple (Faith, Matz, \& Jorge, 2002). Factors such as the severity of depression and obesity, gender, socioeconomic status, life experiences, eating behavior and food cultural patterns, physical activity, stress, quality of relationships, among other variables, may influence the relationship between these problems (Friedman, \& Brownell, 1995). Some authors consider that in the case of tracing a causal link between depression and obesity in adolescents, this could be operating through processes that imply aspects of body image (Roberts, \& Duong, 2015).

Our findings fall into the dynamics of supporting evidence around this lack of clarity in the relationship of the variables, and perhaps this is due to the nature of obesity, the characteristics of the population studied in the present paper (socio-cultural factors), and limitations due to the implemented methodology (tools used). All of these are aspects to be taken into account in future research. Some studies indicate obesity as a risk factor for the presence of depressive symptoms, but not for clinical depression (Boutelle $e t$ al., 2010); others provide evidence of the association between depression and morbid obesity (Stunkard $e t$ al., 2003) and some point out the relationship between the variable of gender groups, being girls the vulnerable group (Carpenter et al., 2000; De Wit et al., 2010). 


\section{LIMITATIONS}

This study presents analysis of anthropometric and psychosocial variables, but genetic and environmental variables that allow further characterization of the population and greater certainty on data obtained are not included. Therefore, it is recommended that future research include such indicators as well as for longitudinal studies to understand the causal patterns of depression in people living with obesity (Faith, et al., 2002).

The present study has some limitations that should be considered in future research. In the first instance we have a non-probabilistic limited sample with a transversal cut, so the extrapolation of the results to a similar population of Spanish speaking adolescents requires contrast. All the findings should be taken as hypothesis. Other aspect to consider is that the age ranges are limited, so we recommend extending them to obtain valid results for general population which can include children and adult population. It is also recommended to seek a representative probabilistic sample of both gender for future research and given the cross-sectional nature of the study, it would be interesting to conduct longitudinal studies to see the relationship between variables in addition to the interaction with other variables that were not considered in the present work. Another limitation is the self-reported nature of the data, which can introduce a degree of imprecision in the responses of adolescents.

We see this study as a starting point for a future research, as it is still a limited number of studies examining the relationship between these variables. Studies about psychological aspects of obesity can be complemented with other instruments for a better understanding on this phenomenon, which can lead in the better design of intervention strategies. Our study aims to contribute to a better characterization of the population of Mexican adolescents, so that the national contingency plans for prevention and intervention in obesity have adequate implementation and achieve greater adherence by patients living with this problem.

\section{Prospective analysis}

The national strategies that are currently being implemented to combat the problem of obesity in Mexico would have to be rethought and reviewed by broad multidisciplinary teams. When working with adolescents, we are really struck by the high number of cases of adolescents with depression, and even more when we see those cases of young participants living with overweight and obesity and depressive symptomatology (more than 50\%). We ask ourselves, "Where does our population go? What is the future for these young people?".

Thinking about the high rates of obesity in Mexico, is not only a matter of intake, but also other problems that are associated with it aggravating the health of people, with the early development of chronic degenerative diseases that some years ago were expected to occur in elderly people. The association between obesity and the development of chronic diseases can be the reason why there is so much concerned about this health problem, which represents a high cost for the health system in every country.

Additionally, we have to think about the impact of the current psychosocial problems experienced in our community on the physical and mental health of our adolescents. Contextualizing, we can say that in the northeast of Mexico we live a situation of violence like never before, we have a strong influence of the neighboring country in reference to feeding and eating habits, a marked tendency to consumerism, fast food restaurants have become popular. Furthermore, the economic situation of families has made it necessary for both parents to have to work, perhaps with the "sacrifice" of leaving the children in the hands of others who care for and feed them, and besides this, nowadays adolescents have more contact with the web than with their families. It is not uncommon to observe people in restaurants and family gatherings who talk to others but not between them. This leads us to ask ourselves, what are we doing wrong?, what are we not listening?, why despite being a developing country do we live with a duality between the lack of resources and purchasing power but high levels of obesity? And what is it that afflicts our society that is reflected in its weight and perhaps in its way of eating? 
For us as researchers it turns out that obesity is a more complex problem than we have wanted to see, we have focused on our trenches and from the perspectives given by our frames of reference, but there is a lack of collegial work to develop effective interventions, which can really impact on improving the health habits of our society, leading them to weight control and emotional well-being. We hope that in the near future, the presence of psychologists in the health scenario as a reality and not a recommendation of our guild acclaiming its inclusion. The disease, in its biopsychosocial dimension, warrants an intervention of the same nature.

Although our work does not give answers, it opens up more questions that allow us to reflect to continue in the search for solutions to the health problems that our country is experiencing.

\section{REFERENCES}

American Psychological Association. (2002). Ethical principles of psychologists and code of conduct. American Psychologist, 57(12), 1060-1073. DOI: 10.1037/0003-066X.57.12.1060

Askari, J., Hassanbeigi, A., Khosravi, H. M. et al. (2013). The relationship between obesity and depression. Procedia-Social and Behavioral Sciences, 84, 796-800. DOI: 10.1016/j.sbspro.2013.06.649

Benjet, C., Borges, G., Medina-Mora, M. E., Zambrano, J., \& Aguilar-Gaxiola, S. (2009). Youth mental health in a populous city of the developing world: results from the Mexican Adolescent Mental Health Survey. Journal of Child Psychology and Psychiatry, 50(4), 386-395. DOI: 10.1111/j.1469-7610.2008.01962.x

Berenzon, S., Lara, M. A., Robles, R., \& Medina-Mora, M. E. (2013). Depresión: estado del conocimiento y la necesidad de políticas públicas y planes de acción en México. Salud Pública de México, 55(1), 74-80.

Blaine, B. (2008). Does depression cause obesity? A meta-analysis of longitudinal studies of depression and weight control. Journal of Health Psychology, 13(8), 1190-1197. DOI: 10.1177/1359105308095977

Boutelle, K. N., Hannan, P., Fulkerson, J. A., Crow, S. J., \& Stice, E. (2010). Obesity as a prospective predictor of depression in adolescent females. Health Psychology, 29(3), 293-298. DOI: 10.1037/a0018645

Carpenter, K. M., Hasin, D. S., Allison, D. B., \& Faith, M. S. (2000). Relationships between obesity and DSM-IV major depressive disorder, suicide ideation, and suicide attempts: results from a general population study. American Journal of Public Health, 90(2), 251. DOI: 10.2105/AJPH.90.2.251

De Wit, L., Luppino, F., van Straten, A., Penninx, B., Zitman, F., \& Cuijpers, P. (2010). Depression and obesity: a meta-analysis of community-based studies. Psychiatry Research, 178(2), 230-235. DOI: 10.1002/da.20738

Faith, M. S., Matz, P. E., \& Jorge, M. A. (2002). Obesity-depression associations in the population. Journal of Psychosomatic Research, 53(4), 935-942. DOI: 10.1016/S0022-3999(02)00308-2

Fitzgibbon, M. L., Stolley, M. R., \& Kirschenbaum, D. S. (1993). Obese people who seek treatment have different characteristics than those who do not seek treatment. Health Psychology, 12(5), 342-345.

Friedman, M. A., \& Brownell, K. D. (1995). Psychological correlates of obesity: moving to the next research generation. Psychological Bulletin, 117(1), 3-20. DOI: 10.1037//0033-2909.117.1.3

Goodman, E., \& Whitaker, R. C. (2002). A prospective study of the role of depression in the development and persistence of adolescent obesity. Pediatrics, 110(3), 497-504. DOI: 10.1016/j.jadohealth.2010.10.015

Keppel,G., \& Wickens, T.D. (2004). Design and analysis: a researcher's handbook. New Jersey, USA: Prentice Hall.

Kessler, R. C., Chiu, W. T., Demler, O., \& Walters, E. E. (2005). Prevalence, severity, and comorbidity of 12-month DSM-IV disorders in the National Comorbidity Survey Replication. Archives of General Psychiatry, 62(6), 617-627.

Lang, M., \& Tisher, M. (1983). Cuestionario de depresión para niños (7th ed). Madrid, España: TEA.

Medina-Mora, M. E., Guiot, E. R., Borges, G., Vázquez-Pérez, L., Bautista, C. F., \& Quintanar, T. R. (2008). Comorbidity: Depression and substance abuse. In Aguilar-Gaxiola, S., \& Gullotta, T. (Eds.). Depression in Latinos (pp. 73-91). USA: Springer. 
Merikangas, A. K., Mendola, P., Pastor, P. N., Reuben, C. A., \& Cleary, S. D. (2012). The association between major depressive disorder and obesity in US adolescents: results from the 2001-2004. National Health and Nutrition Examination Survey. Journal of Behavioral Medicine, 35(2), 149-154. DOI: 10.1007/s10865-011-9340-x

Murray, C. J., \& Lopez, A. D. (1996). Summary: The global burden of disease: A comprehensive assessment of mortality and disability from diseases, injuries, and risk factors in 1990 and projected to 2020. Geneva and Boston: World Health Organization and Harvard School of Public Health.

Onis, M. D., Onyango, A. W., Borghi, E., Siyam, A., Nishida, C., \& Siekmann, J. (2007). Development of a WHO growth reference for school-aged children and adolescents. Bulletin of the World Health Organization, 85(9), 660-667. Retrieved from http://www.who.int/growthref/growthref_who_bull/en/index.html.

Posada-Villa, J., Aguilar-Gaxiola, S., \& Deeb-Sossa, N. (2009). La patología psiquiátrica en Colombia: resultados del estudio nacional de salud mental, Colombia, 2003. In J. Rodríguez, R. Kohn \& S. Aguilar-Gaxiola (Eds.). Epidemiología de los trastornos mentales en América Latina y el Caribe (64-78). Washington: Organización Panamericana de la Salud.

Rafful, C., Medina-Mora, M. E., Borges, G., Benjet, C., \& Orozco, R. (2012). Depression, gender, and the treatment gap in Mexico. Journal of affective disorders, 138(1), 165-169. DOI: 10.1016/j.jad.2011.12.040

Roberts, R. E., \& Duong, H. T. (2015). Does major depression affect risk for adolescent obesity? Journal of Affective Disorders, 186, 162-167. DOI: 10.1016/j.jad.2015.06.030

Roberts, R. E., Deleger, S., Strawbridge, W. J., \& Kaplan, G. A. (2003). Prospective association between obesity and depression: evidence from the Alameda County Study. International Journal of Obesity, 27(4), 514-521. DOI: 10.1038/sj.ijo.0802204

Shaffer, D., Gould, M. S., Fisher, P., Trautman, P., Moreau, D., Kleinman, M., \& Flory, M. (1996). Psychiatric diagnosis in child and adolescent suicide. Archives of General Psychiatry, 53(4), 339-348.

Smith, M. J., \& Perkins, K. (2008). Attending to the voice of adolescents who are overweight to promote mental health. Archives of Psychiatric Nursing, 22(6), 391-393. DOI: 10.1016/j.apnu.2008.08.001

Stunkard, A. J., Faith, M. S., \& Allison, K. C. (2003). Depression and obesity. Biological Psychiatry, 54(3), 330-337. DOI: $10.1016 /$ S0006-3223(03)00608-5

Van Lieshout, R. J., \& MacQueen, G. (2008). Psychological factors in asthma. Allergy, Asthma \& Clinical Immunology, 4(1), 12-28. DOI: $10.1186 / 1710-1492-4-1-12$

Vicente, B., Kohn, R., Saldivia, S., \& Rioseco, P. (2009). Las contribuciones de Chile a la investigación en epidemiología psiquiátrica. In J. Rodríguez, R. Kohn \& S. Aguilar-Gaxiola (Eds.). Epidemiología de los trastornos mentales en América Latina y el Caribe (pp. 118-131). Washington: OPS.

Wardle, J., \& Cooke, L. (2005). The impact of obesity on psychological well-being. Best Practice \& Research Clinical Endocrinology \& Metabolism, 19(3), 421-440. DOI: 10.1016/j.beem.2005.04.006

\section{BY-NC-ND}

